\title{
BORGES Y LA LITERATURA INGLESA
}

\author{
POR \\ ROBERTO PAOLI \\ Università di Firenze
}

Del profundo enlace de Jorge Luis Borges con la lengua y la literatura inglesa, que en sus aspectos anecdóticos es bastante conocido, nos limitaremos a recordar que durante unos veinte años el escritor argentino ha sido profesor de literatura inglesa y norteamericana en la Universidad de Buenos Aires y que su método se fundaba en que la lectura de los autores fuera directa, sin interferencia de críticas, historias literarias y bibliografías. No exigía más que las obras que a cada estudiante le gustaba leer, pues, en su opinión, la lectura es felicidad y no puede haber una felicidad obligatoria ${ }^{1}$.

Ahora, ese método es acaso de más fácil aplicación con la literatura inglesa que con otras literaturas, porque las prerrogativas de la literatura inglesa son para Borges precisamente su poder imaginativo y su «legibilidad» (readableness) ${ }^{2}$. Una obra es «legible» si tiene atractivo argumental y si no es formalmente pesada. En suma, si se hace olvidar como libro. Cuando uno piensa en la literatura inglesa, afirma Borges, acuden a nuestra mente, sobre todo, hombres; si uno piensa en la española, al contrario, acuden libros ${ }^{3}$. Este sería el motivo por el cual la literatura española, cuando no es genial, es tediosa ${ }^{4}$. La literatura inglesa, aun en sus expresiones que no son de primer orden, valora lo que atrae o di-

1 Borges, oral (Buenos Aires: Emecé-Belgrano), 1979, p. 22; Siete noches (México: Fondo de Cultura Económica, 1980), p. 107.

2 Prólogos (Buenos Aires: Torres Agüero, 1975), p. 154; Discusión (Buenos Aires: Emecé, 1969), 5。 ed., p. 93 y pp. 158-159.

3 Richard Burgin, Conversations with Jorge Luis Borges (New York, 1968). (Cito por la versión italiana: Conversazioni con Borges, Milano, Palazzi, 1971, pp. 128-129).

4 El idioma de los argentinos (Buenos Aires: Gleiser, 1928), p. 174. 
vierte al lector: el sueño, la aventura, el misterio. E1 género policial halló necesariamente la savia más fecunda para su desarrollo en esta tierra de elección de la narrativa más agradable y cautivante ${ }^{5}$.

En varias ocasiones, Borges ha subrayado el vínculo natural entre Inglaterra y el mar, «pampa de los ingleses». Estos perciben el mar como los argentinos perciben la llanura. Cuando se ponen en discordia con la familia, amenazan huir al mar, run away to sea ${ }^{6}$. Tan identificado con el mar ve Borges el destino inglés, que en un verso de su libro de poemas La cifra, dice: «El que mira el mar ve a Inglaterra» ${ }^{7}$. Esta isla, desgarrada por el mar, estaba, pues, predestinada a expresar una literatura devota del mar» ${ }^{\circ}$. Es éste un tema eterno en la literatura inglesa, desde las antiguas elegías anglosajonas hasta Kipling y Conrad", y bastarían para probarlo las numerosas versiones de la Odisea que se han hecho en Inglaterra ${ }^{10}$. De esa condición de pertenecer a un pueblo de navegantes y viajeros, los escritores ingleses han sacado su especial inclinación a captar e interpretar el modo de ser de otros pueblos: piénsese en Richard Burton y Arabia, en Lafcadio Hearn y el Japón, en William Henry Hudson y los países del Río de la Plata, en George Borrow y España ${ }^{11}$.

Aunque reparáramos sólo en la poesía, está claro que Borges se aparta de la tradición lírica hispanoamericana y española, que, por lo general, ha preferido la tradición francesa a la inglesa. Para él (pero no está completamente solo: se le deben juntar, por lo menos entre los españoles, Unamuno y Cernuda) el parnaso inglés ha tenido una importancia mucho mayor que el francés ${ }^{12}$. Una razón de tal preferencia es que el poeta inglés, según opinión de Borges, escribe en función de su propia imaginación y no en función de la historia, como suele hacerse en

5 Borges, oral, op. cit., pp. 77-78.

${ }^{6}$ Discusión, op. cit., p. 16; Borges el memorioso (Conversaciones con A. Carrizo) (México-Buenos Aires: Fondo de Cultura Económica, 1982), p. 281; Historia universal de la infamia (Buenos Aires: Emecé, 1969), 8." ed., p. 31.

${ }^{7}$ La cifra (Madrid: Alianza Editorial, 1981). Cito por la edición italiana bilingüe (Milano: Mondadori, 1982), p. 58.

8 Borges el memorioso, op. cit., p. 110.

9 María Esther Vázquez, Borges, imágenes, memorias, diálogos (Caracas: Monte Avila), p. 152.

10 Discusión, op. cit., p. 107.

11 El tamaño de mi esperanza (Buenos Aires: Proa, 1926), pp. 31-36; Otras inquisiciones (Buenos Aires: Emecé, 1968), 4. ${ }^{a}$ ed., p. 198.

${ }_{12}$ An Autobiographical Essay, recogido por-N. T. Di Giovanni (New York, 1970). Cito por la versión italiana: Abozzo di autobiografia, en el apéndice de Elogio dell'ombra (Torino: Einaudi, 1971), pp. 181-182. 
Francia ${ }^{13}$. Sabido es que a Francia nuestro escritor le achaca la responsabilidad de haber impuesto al mundo su peculiar modelo de vida literaria, o sea, la división en grupos rivales, y la necesidad de militar en la vanguardia, ya que, en la óptica francesa de la historia, la literatura estaría siempre renovándose. En la literatura británica, en cambio, conforme a ese aforismo de Novalis según el cual cada inglés es una isla, puede comprobarse efectivamente esa ley de la insularidad, pues por to general los individuos aislados prevalecen sobre las escuelas, los movimientos y los manifiestos literarios ${ }^{14}$.

Entiendo que el mayor tesoro que Borges ha hallado, o ha creído hallar en esa inmensa isla literaria, es una gran cantidad y variedad de argumentos fantásticos, visionarios y oníricos. Su trato con la literatura inglesa es, en un buen porcentaje, un trato con el tiempo mágico, con el tema del doble, con el sueño, con la pesadilla o con una realidad que se presenta a menudo misteriosa y como teñida de irreal. De todos los dramas de Shakespeare, el que más cita y admira es Macbeth, pues se trata de una tragedia que, como él dice, «se impone a quienes la ven, la recorren o la recuerdan, con la atroz convicción de una pesadilla» ${ }^{15}$. Con respecto a la literatura del siglo siguiente, no pueden dejar de impresionarlo las invenciones fantásticas de los Viajes de Gulliver, que han influido de una forma manifiesta ( $\mathrm{y}$ a veces confesada) ${ }^{16}$ sobre cuentos como «Tlön, Uqbar, Orbis Tertius», «E1 inmortal» y El informe de Brodie; sin embargo, el intento satírico de Swift, aunque sea compartido por el escritor argentino, no pasa a sus cuentos, que están exentos de toda finalidad moralizante.

El alma de Borges, clásica en su conciencia formal, no queda, por eso, insensible al elemento romántico y demoníaco. Esa notable, y sorprendentemente concorde, duplicidad se evidencia, en él, en dos operaciones esenciales: a) traducir lo fantástico en fábulas de lúcida racionalidad; b) valorar (o revalorar) obras del pasado que pertenecen al filón fantástico. Sólo en este sentido (de un doble plano anímico) puede explicarse que al lado de la historia y autobiografía de Edward Gibbon se

13 Borges en diálogo (Conversaciones con O. Ferrari) (Buenos Aires: Grijalbo, 1985), p. 36.

14 Discusión, op. cit., p. 51; An Autobiographical Essay, edic. ital. cit., p. 167; El escritor y su obra (Entrevistas de G. Charbonnier con J. L. Borges) (México: Siglo XXI, 1970), 2. a ed., pp. 22-24; «Introducción a la literatura inglesa», en Obras completas en colaboración (Buenos Aires: Emecé), p. 807; «Borges en diálogo», op. cit., p. 223.

15 Prólogos, op. cit., p. 146.

16 Borges el memorioso, op. cit., p. 302. 
halle, entre sus preferencias del siglo XviII, un cuento tan diferente como el Vathek, de William Beckford, que preanuncia notoriamente a románticos y decadentes (De Quincey, Poe, Huysmans, etc.). En el artículo que dedica al Vathek en Otras inquisiciones, Borges destaca el horror de pesadilla y el satánico esplendor del Alcázar del Fuego Subterráneo, en cuya descripción se acaba el relato. El intraducible epíteto inglés uncanny no es aplicable a ningún libro anterior al Vathek, cuyo infierno final es el «primer Infierno realmente atroz de la literatura». En efecto, «el más ilustre de los Avernos literarios», el dantesco, no es, en el parecer de Borges, «un lugar atroz», sino solamente «un lugar en el que ocurren hechos atroces» ${ }^{17}$.

La figura del primer romanticismo con la que nuestro autor mayormente se identifica es la de Coleridge, a quien cita a menudo por muchos aspectos, pero sobre todo por ser el creador del mejor poema de inspiración fantástica y onírica. Se trata de Kubla Kan, ese fragmento lírico que Coleridge dice haber recibido durante un sueño y que le parece a Borges, «por las imágenes y por la delicada cadencia, una de las páginas inmortales de la literaturas ${ }^{18}$. Estos versos le han sugerido otra famosa página de sus prosas, «El sueño de Coleridge», en la que se sutiliza encantadoramente sobre el origen onírico de algunas obras de arte (desde $I l$ tritlo del diavolo, de Tartini, hasta Dr. Jekyll and Mr. Hyde, de Stevenson) y sobre los sucesivos avatares de un mismo arquetipo onírico ${ }^{19}$. Kubla Kan, entre los textos de Coleridge relacionados con el sueño, no es el único que haya llamado la atención de Borges. Hay un breve fragmento que ha motivado otro admirable artículo: «La flor de Coleridge». El fragmento reza de esta forma: «Si un hombre atravesara el Paraíso en un sueño, y le dieran una flor como prueba de que había estado allí, y si al despertar encontrara esa flor en su mano... \&entonces, qué?» Borges relaciona dicha frase con la novela de Wells, The Time Machine, cuyo protagonista trae una flor al volver de un viaje físico al lejano porvenir. La novela de Wells, a su vez, habría inspirado - según el mismo artículo- la de Henry James, The Sense of the Past, que relata otro viaje en el tiempo (en este caso, hacia el pasado ${ }^{20}$.

Muchas cosas Borges confiesa deberle a Thomas de Quincey, pero indudablemente lo que mejor parece haber aprendido de este hombre singular, inclinado a las fantasías, es el manejo de la dimensión onírica, pues De Quincey es para él, sobre todo, un escritor de gran fuerza visio-

17 Otras inquisiciones, op. cit., pp. 190-191.

${ }_{18}$ Introducción a la literatura inglesa, op. cit., p. 832.

19 Otras inquisiciones, op. cit., p. 26.

20 Ibidem, pp. 20-21. 
naria y maestro de la pesadilla y del horror. De los grandes exploradores de la vida de los sueños (incluyendo al mismo Poe) De Quincey es su favorito, y la ejemplaridad de Confessions of an English Opium Eater está subrayada repetidas veces por medio de puntuales referencias. E1 magisterio proporcionado por De Quincey como narrador de sueños y de sus fantásticos escenarios, como mente congenial en la imaginación y descripción de laberintos y arquitecturas piranesianas, recibe su pleno reconocimiento en los versos del poema «A cierta sombra, 1940». Con vigor emotivo Borges invoca la sombra del gran escritor inglés para que socorra a su patria agredida por naciones enemigas:

Vuelve a soñar, De Quincey. / Teje para baluarte de tu isla / Redes de pesadilla. / Que por sus laberintos de tiempo / Erren sin fin los que odian. / ... ... / Que nos salven ahora las indescifrables arquitecturas / Que dieron horror a tu sueño. / Hermano de la noche, bebedor de opio, / Padre de sinuosos períodos que ya son laberintos y torres, / Padre de las palabras que no se olvidan, / iMe oyes, amigo no mirado, me oyes / A través de esas cosas insondables / Que son los mares y la muerte? ${ }^{21}$.

Hay en De Quincey, además, un interés por el ocultismo y la magia, que no ha estimulado menos la fantasía de Borges. Un breve pasaje de Suspiria de Profundis, en el que se alude a la «jactancia de Paracelso, que afirmaba poder resucitar la rosa o la violeta originarias de las cenizas de su combustión», ha inspirado: a) la imagen de «la rosa que resurge de la tenue / ceniza por el arte de la alquimia», en el poema «La rosa» $(22)$; b) el cuento «La rosa de Paracelso», donde el escritor argentino ha transformado en ficción la vaga traza proporcionada por De Quincey ${ }^{23}$.

Finalmente, otro motivo dequinciano, si bien común a varios autores, que ha debido impresionar a Borges, concierne a la posibilidad, en circunstancias excepcionales, de una dilatación del tiempo o de una resurrección simultánea del mismo, o sea de la inserción de un tiempo mágico (o que puede parecer mágico) en la trama del tiempo ordinario: una vez más, ciertas experiencias visionarias, que están relatadas en las Confessions of an English Opium Eater, en Suspiria y en The English Mail Coach, han penetrado en cuentos como «El milagro secreto» o «La otra muerte», que tienen por tema central el complejo problema del tiempo.

21 Obra poética (1913-1976) (Madrid: Alianza Tres/Emecé, 1979), pp. 333-334.

22 Ibidem, p. 38.

23 El cuento lleva en su epígrafe la referencia exacta a: Collected Writings, XIII, 345. 
En toda la literatura moderna, Lewis Carroll es tal vez el único escritor que haya realizado el singular proyecto que se había propuesto $\mathrm{Ha}^{\prime} \mathrm{w}$ thorne: escribir un sueño "que fuera como un sueño verdadero, y que tuviera la incoherencia, las rarezas y la falta de propósito de los sueños» ${ }^{24}$. Borges leyó, en su niñez, los cuentos de Alicia, pero confiesa que no logró aprehender inmediatamente la sensación de pesadilla que los penetra ${ }^{25}$. Más tarde, el ajedrez onírico de Through the LookingGlass ha llegado a ser una de las invenciones literarias que más lo han atrapado en sus numerosas magias: el ajedrez del mundo, las metamorfosis, la carrera inmóvil, el sueño recíproco, los sueños contenidos en otros sueños, los juegos con el tiempo invertido y con el tiempo bloqueado, las paradojas lógico-matemáticas, los dobles sentidos ligados al lenguaje común. Y precisamente con Through the Looking-Glass (en modo especial, con el episodio del Rey Rojo que sueña y con la pregunta del capítulo final: «¿Quién lo ha soñado?») se relaciona la notoria perplejidad borgesiana acerca de quién sea verdaderamente el sujeto y el objeto del sueño: perplejidad que ha inspirado, por ejemplo, un artículo como «Magias parciales del Quijote», o un cuento como «Las ruinas circulares», cuyo epígrafe (And if he left off dreaming about you... "Y si dejara de soñarte...») es fundadamente carrolliano. Cuando leemos las últimas palabras de Alicia («Ahora, Kitty, tratemos de comprender quién soñó todo eso... O fui yo o fue el Rey Rojo. El formó parte de mi sueño, naturalmente, pero entonces yo también formé parte del suyo»), y, luego, en el último renglón, el irónico desafío con que Carroll acaba la historia ( $Y$ Y para ustedes, ¿quién soñó todo eso?»), nosotros sabemos que en la pregunta está contenido uno de los centrales problemas metafísicos que Borges ha aprovechado literariamente, y que el autor de Alicia ha sido importante para él, mucho más de lo que atestiguan las referencias directas ${ }^{26}$.

Referencias directas abundan, en cambio, en el caso de Robert Louis Stevenson, a quien nuestro escritor considera no sólo como modelo literario, sino también como un amigo íntimo, una forma de la felicidad que la suerte le ha adjudicado. Y se vale, en particular, del relato del Dr. Jekyll and Mr. Hyde para poner de relieve algunos de los rasgos distintivos de su amado narrador: por ejemplo, una vez más, el sueño. Con este motivo observa que Stevenson, en su Chapter on Drearns, «refiere que en los sueños de la niñez lo perseguía un matiz abominable

\footnotetext{
24 Otras inquisiciones, cit., p. 92.

25 Richard Burgin, Conversations..., ed. ital. cit., pp. 66-67.

26 Prólogos, cit., pp. 108-111.
} 
de color pardo» ${ }^{27}, \mathrm{y}$, además, que fueron precisamente dos sueños a darle el argumento de Olalla y del Dr. Jekyll ${ }^{28}$. Obviamente, el sueño le había concedido, de este último relato, sólo una escena, la de la transformación, pero fue suficiente para que la imaginación pudiera hacer lo demás ${ }^{29}$. El tema fantástico de esta pequeña obra maestra, el tema del doble, tiene, pues, un origen onírico, de modo que son tres los elementos que indican como punto de partida los cuentos de Edgar Allan Poe: el doble, la pesadilla y la intriga policial. En efecto, cuando el Dr. Jekyll se publicó por primera vez, fue leído como si fuera un relato policial, y el lector quedaba asombrado, al final, descubriendo que los dos personajes del título eran la misma persona ${ }^{30}$. En cambio, la película de Victor Fleming, al revelar inmediatamente tal identidad, es, en opinión de Borges, sólo una torpe deformación de un cuento magis$\operatorname{tral}^{31}$.

En cuanto al difundido motivo del doble, que, como dice en el epílogo del Libro de arena, «movió tantas veces la siempre afortunada pluma de Stevenson», Borges advierte que no es suficiente recurrir a los antecedentes literarios (Poe, Hoffmann, Dostoevskij), sino que hace falta recordar asimismo el mito popular céltico-escocés del fetch, en que se ha inspirado Stevenson para el Dr. Jekyll y para otros admirables cuentos como Thrawn Janet y Barkheim. Se le preguntó a Borges cuál era la ascendencia de sus cuentos «El otro» y «25 Agosto 1983», ambos basados en la iỏea del doble ${ }^{32}$, y él no dudó en relacionarlos con el Dr. Jekyll, pasando por alto cualquier otra posible influencia o coincidencia ${ }^{33}$. Hasta el breve e intenso fragmento «Borges y yo» de $E l$ hacedor, habría nacido, según el autor, bajo el signo del Dr. Jekyll, si bien con alguna simplificación y atenuación: «Borges», personificando al hombre público, es un poco el odioso e inhumano Hyde, mientras «Yo», personificando al hom-

27 Otras inquisiciones, cit., p. 190.

28 Ibidem, p. 26.

29 Introducción a la literatura inglesa, cit. p. 845.

30 Ibidem, p. 845; María Esther Vázquez, op. cit., p. 129.

31 Discusión, cit., pp. 179-180.

32 Según Daniel Balderston ( $E l$ precursor velado; R. L. Stevenson en la obra de Borges, Buenos Aires, Ed. Sudamericana, 1985), la idea del doble se halla también en "Tema del traidor y del héroe», pero advierte que el cuento borgesiano no «postula la identidad de dos personas distintas, sino la coexistencia en una persona de dos posibilidades o tendencias contradictorias (heroísmo y traición)» (p. 99). En este sentido extensivo, sin embargo, los ctientos de Borges que caen dentro de la categoría del «doble» son numerosos: «La otra muerte» es el principal.

33 El libro de arena (Madrid: Ultramar-Emecé, 1975), p. 179. 
bre auténtico y secreto, representa el papel comparativamente humano (aunque en sí mismo ambiguo) de Jekyll ${ }^{34}$.

Inglaterra, especialmente con Herbert George Wells, debe considerarse la patria de la ciencia-ficción. Wells ha sido una de las primeras lecturas de Borges. Entre los libros que más impresionaron su imaginación infantil figuran The Time Machine y The First Men in the Moon. Desde el punto de vista de la fantasía científica, los primeros libros de Wells no han sido superados ${ }^{35}$. Tanto admira Borges esta etapa creadora del escritor inglés, que le ha dedicado una de sus páginas críticas más atinadas, titulada «El primer Wells» ${ }^{36}$. En el artículo, después de subrayar los vínculos que unen el mundo de Wells al de Swift y al de Poe, reconoce la superior validez de este prodigioso período, no sólo por la genialidad de los hallazgos narrativos, sino sobre todo por la capacidad de proveerlos de poder alusivo a hechos relacionados con el humano destino: ese simbolismo, nunca manifiesto, nunca descarado, nunca razonado, sino tan sólo sugerido, es el mérito de los primeros libros de Wells. "Con esa lúcida inocencia», cito las palabras mismas de Borges, «obró Wells en sus primeros ejercicios fantásticos, que son, a mi entender, lo más admirable que comprende su obra admirable» ${ }^{37}$.

Uno de los cuentos de este período, «The Crystal Egg», habría ejercido algún influjo en los cuentos de Borges «El Zahir» y «El Aleph», según admisión del mismo autor ${ }^{37}$. En efecto, también en el cristal del relato inglés podemos notar el multum in parvo: el objeto resplandece de luz propia, el mundo por él revelado encierra otros huevos de cristal, y a través de uno de ellos, seres de otro planeta nos espían. Este último detalle presagia, de alguna manera, la magia principal del Aleph de Borges: la de ser continente y contenido. Pero hay una diferencia esencial. El cristal de Wells es un instrumento mágico que nos da un atisbo de un mundo de fantasía científica, donde se mueven criaturas extraterrestres. Al contrario, las visiones que se alcanzan simultáneamente en el Aleph, nada tienen que ver con la ciencia-ficción, pues conciernen a nuestro mismo mundo, más desconocido y secreto que un astro inexplorado: dichas visiones se parecen, más bien, a una experiencia mágica de

${ }^{34}$ Borges at Eighty, edición de W. Barnstone (Indiana University Press, 1982). Cito por la versión italiana: Conversazioni americane (Roma: Editori Reuniti, 1984), p. 60.

35 Evaristo Carriego (Buenos Aires: Emecé, 1969), 5. ed., p. 9; Prólogos, cit., p. 27; «Introduzione» a H. G. Wells, La porta nel muro (Parma: F. M. Ricci, 1980), p. 9.

36 Otras inquisiciones, cit., pp. 125-128.

${ }^{37}$ El Aleph (Buenos Aires: Emecé, 1969), 11.a ed., p. 178. 
carácter místico, semejante a la que describe el lama rojo en el último capítulo de la novela Kim de Kipling. A veces ocurre que Borges, sin darse cuenta, contamina las fuentes, y la que él indica, aunque a su conciencia aparezca como la sola que haya actuado, no resulta ser objetivamente la más importante.

Un escritor como Wells es, en Gran Bretaña, la cumbre eminente de una serie de figuras que constituyen una verdadera tradición de literatura fantástica (y fantástico-científica). Es una razón de ello que la colección «La Biblioteca de Babel», dirigida por Borges, ha propuesto (o vuelto a proponer) numerosos escritores británicos a la atención del público: se encuentran el fantástico-científico Charles Howard Hinton, autor de los Scientific Romances (1888), y a quien se considera un precursor de Wells; el visionario galés Arthur Machen, autor de The Three Impostors; el onírico irlandés Lord Dunsany, precursor de Kafka y de Buzzati en su relato Carcassonne; el cosmopolita y extravagante Saki. Entre los no incluidos hay dos discípulos de Wells, a quienes Borges señala en otras ocasiones: Olaf Stapledon y Clive Staples Lewis, cuya novela Out of the Silent Planet (1938) ha sido importante para ciertos aspectos de la concepción de «Tlön, Uqbar, Orbis Tertius», como advierte Borges mismo y ha puesto en gran evidencia Rodríguez Monegal ${ }^{38}$. En cuanto a las conocidas compilaciones realizadas en colaboración, como la Antología de la literatura fantástica, Cuentos breves y extraordinarios, El libro de los seres imaginarios, es casi superfluo advertir que las fuentes inglesas, antiguas y modernas, son preponderantes. Lo cual es debido, manifiestamente, al concurso de dos factores: el más extenso conocimiento que Borges tiene de la literatura inglesa y la objetiva extensión que en ella lo fantástico ocupa.

Hasta en el teatro de George Bernard Shaw Borges ha buscado y valorado lo fantástico. Las dos piezas más recurrentes en su memoria son Man and Superman y Back to Methuselah. En la primera, lo que más lo ha impresionado es el sueño de Don Juan en el tercer acto, que se imagina acontecer en un infierno disconforme de las representaciones tradicionales. En la segunda, la idea de una vida extremadamente longeva o inmortal, tal como aparece en la última parte (As far as Thought can reach), ha sugerido, según lo indicado por el mismo autor ${ }^{39}$, algunos

38 An Autobiographical Essay, ed. ital. cit., p. 174; Emir Rodríguez Monegal, J. L. Borges. A Literary Biography, New York, Dutton, 1978. Cito por la versión italiana: Borges. Una biografia letteraria, Milano, Feltrinelli, 1982, pp. 313-314 y 318-320.

${ }^{39}$ El Aleph, cit., p. 26. 
pasajes del cuento «El inmortal», donde dice que los inmortales, "absortos, casi no percibían el mundo físico» y sabían «que en un plazo infinito le ocurren a todo hombre todas las cosas».

Discurriendo de literatura fantástica, no podemos prescindir de hacer alguna alusión al género policial, ya que es en Inglaterra donde se realiza, según Borges, un acercamiento, y hasta una suerte de fusión, entre las dos tendencias. Eso ocurre principalmente gracias a Chesterton, pero también por obra de otros autores, en particular de Stevenson, no sólo en su Dr. Jekyll, sino también en su novelesco New Arabian Nights, que nos revela un Londres fantástico que se anticipa a las atmósferas policiales típicas de Chesterton. Excelente conocedor de las dos mayores literaturas de lengua inglesa, Borges ha sentido un especial interés por el relato policial, que, si bien es creación del norteamericano Poe, ha conocido en Gran Bretaña un desarrollo sobremanera fecundo, debido a las plumas de Dickens, Collins, Stevenson, Conan Doyle y, singularmente, de Chesterton: el más ilustre discípulo de Poe, en opinión de Borges, y hasta superior al maestro.

Para confirmar la primacía británica en este género, la segunda antología de Los mejores cuentos policiales, compilada por Borges y Bioy Casares en 1962, incluye doce autores de lengua inglesa, en un total de catorce: nueve británicos y tres norteamericanos. Borges ama el género, porque ha creado un nuevo tipo de lector, incrédulo y suspicaz. A consecuencia de eso, el autor de relatos policiales no puede dejar nada al azar y está obligado por las exigencias específicas del género a una gran coherencia y a un gran rigor, virtudes que la literatura moderna cultiva cada vez menos. Por tanto, en un siglo como el nuestro que tiende a lo caótico en todas las artes, la ficción policial constituye un freno saludable, un llamamiento a las virtudes clásicas de la organización y del diseño. En suma, la ficción policial está salvando el orden en una época de desorden. Desgraciadamente, agrega Borges, sus posibilidades se agotan con el tiempo, como acontece con todos los géneros muy codificados. En efecto, hoy está en descenso, reemplazada por la ciencia-ficción ${ }^{40}$.

Pero, volviendo a Chesterton, Borges está convencido de que la pesadilla era la forma esencial de su imaginación, no diversamente de Poe y de Kafka, aunque no quiso semejar a estos escritores y trató de parecer afable y feliz. Exaltaba los milagros de la inocencia y se cargaba de optimismo y fe, pero sus creaciones denuncian una especial sensibilidad por el lado horrible y atroz de las cosas, una suerte de oscura inclinación a lo demoníaco y a lo teratológico. Y eso tanto más impresiona

40 María Esther Vázquez, op. cit., pp. 117-123; Borges, oral, cit., pp. 65-80. 
cuanto más ordinario es el ámbito social y topográfico de sus cuentos, cuanto más usuales son los objetos que lo llenan, cuanto más festivo es el tono que toma el narrador. Significativamente, la más famosa de sus novelas, The Man who was Thursday, lleva como subtítulo A Nightmare («Una pesadilla») y es, realmente, una pesadilla grotesca y metafísica, no menos onírica y absurda que las aventuras de Alicia, a las cuales, por otro lado, remite expresamente. En esta obra Borges destaca, de un modo especial, la monstruosa ambigiedad (y la fuerza alusiva) del personaje llamado Sunday, además de esa referencia fabulosa y misteriosa que se halla en el comienzo del sexto capítulo, cuando Syme imagina «que en los confines occidentales del mundo acaso existe un árbol que ya es más, y menos, que un árbol, y en los confines orientales, algo, una torre, cuya sola arquitectura es malvada» ${ }^{41}$. Insiste en mostrar cómo la materia policial de esta novela está poderosamente renovada por Chesterton.

En efecto, mientras Poe distinguía tajantemente entre cuentos fantásticos, que no admiten intervención alguna del investigador Dupin, y cuentos policiales, en los que, al final, el razonamiento proporciona la solución del misterio, Chesterton tuvo la feliz idea de combinar en un mismo cuento el elemento fantástico y el policial: las explicaciones sobrenaturales están reemplazadas al final por otras de orden lógico, pero, no obstante el mecanismo policial, se desliza por debajo del relato una corriente secreta que siempre alude a una dimensión espiritual y mística. Chesterton es el mejor heredero de Poe, y, en virtud de esa acertada combinación, inclusive es superior al maestro. Si el género policial tiende a agotarse ( $\mathrm{y}$ acaso a desaparecer) como resultado de su extremada artificiosidad, los cuentos de Chesterton probablemente se salvarán gracias a su componente fantástico, ya que en ellos el misterio no se deja vencer del todo y lo insoluble no es menos interesante que la solución lógica que parece triunfar en las últimas líneas. A más de eso, Chesterton, tan apegado por lo general a las aldeas inglesas y a los tranquilos suburbios de Londres, le gusta a Borges porque ha sabido respetar la verdadera tradición policial, lo cual no ha ocurrido, por cierto, en América, donde el espíritu de Poe ha sido traicionado por la inserción de ingredientes espurios como la violencia y el sexo ${ }^{42}$.

Para reafirmar la esencial fidelidad de Chesterton a los patrones transmitidos por Poe, Borges cita un par de veces el caso del cuento

41 Otras inquisiciones, cit., p. 190. Sobre Chesterton cfr. además: Otras inquisiciones, pp. 119-123; Roberto Alifano, Conversaciones con Borges (Buenos Aires, Atlántida, 1984), pp. 11-18.

42 Roberto Alifano, op. cit., p. 17. 
«The Invisible Man» (contenido en la serie The Innocence of Father Brown), que recuerda claramente el tema de la carta robada: el asesino es insospechable, porque es el cartero, o sea, un hombre mentalmente invisible ${ }^{43}$. Pero podríamos decir que todas las Father Brown Stories, a pesar de la evolución que el cuento policial sufre bajo la pluma de su autor, a pesar de que se trata en realidad de cuentos fantásticos cuya solución policial resulta a veces un poco forzada, se sitúan en la más noble tradición del cuento corto que deriva de Poe: cada uno de estos relatos es un ejemplo de cuidadosa construcción, donde todo antecedente está relacionado con lo subsiguiente de una manera rigurosa, y nada, absolutamente nada, está dejado al azar ${ }^{44}$.

Borges, autor magistral de piezas narrativas cortas, considera que es Inglaterra la verdadera patria de este género, donde la trama y las situaciones importan más que los caracteres de los personajes. Un escritor como Henry James (a quien Borges incluye también en la Introducción a la literatura inglesa, pues considera que vivió en un contexto vital y cultural inglés, a despecho de su nacimiento americano) alcanza, especialmente en sus últimos cuentos, esa superior esencialidad que no se puede alcanzar en la novela ${ }^{45}$. Pero los maestros absolutos del cuento breve son, en opinión de Borges, Stevenson, Kipling y Chesterton.

Kipling escribió novelas y poemas, pero consiguió sus mejores aciertos en el ámbito del cuento. Por ejemplo, sus primeros ensayos narrativos, especialmente los contenidos en Plain Tales from the Hills, son pequeñas obras maestras, muy inmediatas y verbalmente sobrias, que, según confesión de Borges, han influido decididamente sus cuentos, a partir del Informe de Brodie ${ }^{46}$. En cierto punto de su trayectoria de narrador (que corresponde más o menos a la pérdida de la vista) Borges se negó, o tuvo que negarse, a seguir la pauta de Ficciones y del Aleph (donde, a su ver, hay piezas, como «El inmortal», cuya ejecución le parece demasiado lujosa, barroca, overwritten) e intentó un modo de contar más simple y directo, modelado en la pauta del primer Kipling, el de los plain tales ${ }^{47}$. Ese cambio de dirección en la prosa, a partir del Informe de Brodie, es un hecho, por otro lado, bien reconocible (y conocido por todo lector borgesiano). Obviamente, la lección de Kipling, como autor de cuentos, no se limita a esta fase tardía de Borges, quien declara haber aprendido en él reglas esenciales del arte de narrar, como la de «referir los hechos

\footnotetext{
43 Ibidem, pp. 13-14.

44 Discusión, cit., p. 90.

45 Borges at Eighty, edic. ital. cit., p. 120.

46 El informe de Brodie (Buenos Aires: Emecé, 1970), p. 7.

${ }^{47}$ Borges at Eighty, ed. ital. cit., p. 51.
} 
como si no los entendiera del todo» ${ }^{48}$, y otros ocultos milagros de su admirable artesanía, debido a los cuales «cada uno de sus concisos relatos tiene la riqueza y la densidad de una larga novela» ${ }^{49}$.

Pero cuando habla del arte de Kipling, Borges nunca se olvida de exaltar los últimos relatos de este escritor. En efecto, a su parecer, después de los cuentos de la India y las otras numerosas colecciones intermedias, Kipling, lejos de declinar, supo enriquecerse y renovarse en sus últimos relatos, que recogió bajo el título general de Limits and Renewals (1932). Algunos de ellos, como "The Wish House», «The Eye of Allah», «The Gardener» (que, junto con otros de la plena madurez, Borges ha incluido en el volumen dedicado a Kipling en la colección «La Biblioteca de Babel»), son, en su concepto, no sólo de los más altos y complejos de este escritor, sino textos que, por su polisemia, por su clima laberíntico y angustioso, hallan un término de comparación sólo en las mejores páginas de Kafka o de Henry James ${ }^{50}$.

También en el caso de Chesterton, Borges opina que su mayor título de gloria se funda en que es uno de los grandes maestros del cuento breve. Se ha acusado a nuestro siglo - afirma Borges - de ser incapaz de inventar tramas interesantes, pero nadie ha tenido la paciencia de comprobar que si en algo nuestro siglo se aventaja a los anteriores, es por las tramas. Como ideador de enredos, Chesterton no tiene competidores: el mismo Stevenson «es más apasionado, más diverso, más lucido, quizá más digno de nuestra absoluta amistad que Chesterton; pero los argumentos que gobierna son inferiores» ${ }^{51}$. Baste pensar en el cuento «The Three Horsemen of Apocalypse», una suerte de partida de ajedrez, urdida a lo largo de un camino blanco, con húsares blanos ${ }^{52}$. Pero Chesterton, a más de ser un hábil manipulador de la sintaxis del relato, es también un espléndido descriptor, y su prosa es admirablemente visual, pues ha logrado trasladar a la representación verbal sus dones y su aprendizaje de pintor y dibujante ${ }^{53}$.

Las letras inglesas cuentan con algunos autores que han desarrollado asombrosamente las técnicas modernas del punto de vista y de la ambi-

48 Obra poética (1923-1976), p. 315.

49 «Introduzione» a R. Kipling, La casa dei desideri (Parma: F. M. Ricci, 1979), p. 12.

${ }^{50}$ El informe de Brodie, cit., p. 7; María Esther Vázquez, op. cit., p. 155; Borges el memorioso, cit., p. 297; Borges en diálogo, cit., pp. 217-225.

51 Prólogos, cit., p. 23.

52 «Introduzione» a G. K. Chesterton, L'occhio di Apollo (Parma: F. M. Ricci, 1979), p. 10.

53 Ibidem, p. 9. 
güedad. Es curioso que fuera un poeta el iniciador de esta modalidad, un poeta muy querido de Borges: Robert Browning. En las Conversations with J. L. Borges, de Richard Burgin, leemos esta declaración: «Creo haber revelado Robert Browning a muchos jóvenes en Buenos Aires, donde nadie sabía nada de él... Cuando les conté la trama de sus poemas, mis estudiantes eran literalmente entusiastas por ellos. Pero, luego, al leerlos, los encontraron fatigosos. Sin embargo, si usted cuenta a alguien el argumento de The Ring and the Book, lo encontrará muy interesante. La idea de un acontecimiento narrado por diferentes personajes y desde diferentes ángulos podría ser, más o menos, lo que Henry James hubiera querido hacer mucho antes que Henry James. $Y$ aunque es verdad que hoy casi nadie lo lee, si no es por deber, yo creo que Browning ha sido de veras un precursor de escritores como Henry James y Kafka, y que merecería que se lo leyera con placer» ${ }^{54}$. No se olvida Borges de recordar otro antecedente de esta técnica, aun anterior a Browning, o sea, la novela policial The Moonstone, de Wilkie Collins, donde los diversos personajes que cuentan sucesivamente la historia, crean un contraste dramático de puntos de vista. Cree Borges que el procedimiento deriva de la novela epistolar del siglo Xvin, pero que su reformulación moderna se debe a Collins y a Browning, para pasar luego a Henry James, a Faulkner y al japonés Akutagawa, traductor de Browning y autor del cuento «En el bosque», que ha llegado a ser famoso en su versión cinematográfica como Rashomon ${ }^{55}$.

Pero el ejemplo más clásico de narración ambigua es, indudablemente, The Turn of the Screw, de Henry James, relato (o novela corta) cuyo admirable argumento no ha sido superado en alguna otra época ${ }^{56}$. Sin embargo, ¿conocemos el verdadero argumento de esta obra maestra? $\mathrm{Ni}$ el mismo James podría revelárnoslo; es, como otros cuentos suyos, deliberadamente ambiguo, es decir, inspirado en una precisa poética de la ambiguiedad. Así como el conde Ugolino, en su Torre del Hambre, "devora y no devora los amados cadáveres» de los hijos, de acuerdo con la «ondulante imprecisión» exigida por Dante, James quiso que el cuento consintiera dos distintas interpretaciones, sin comprometerse con ninguna ${ }^{57}$. En uno de sus coloquios, Borges ha explicado, de una forma detallada, cómo llegó a concebir su conocido cuento «El sur» por influjo

54 Edic. ital. cit., pp. 69-70.

55 Prólogos, cit., pp. 47-48.

56 Ibidem, p. 23.

57 Nueve ensayos dantescos (Madrid: Espasa-Calpe, 1982), pp. 110-111. Introducción a la literatura inglesa, p. 850. 
de The Turn of the Screw (que estaba leyendo en aquel entonces): en efecto, «El sur», a semejanza de su modelo técnico (argumentalmente, las dos narraciones no tienen nada en común), admite diferentes posibilidades de explicación ${ }^{58}$.

Otro caso de ambigüedad nos lo ofrece el cuento «The Abasement of the Northmores», que, en concepto de Borges, es tal vez el mejor cuento de Henry James. La narración excita cada vez más la curiosidad del lector, sin satisfacerla nunca, pues la conclusión es vaga, como en El sur borgesiano: una vaguedad calculada, en ambos casos, por el preciso plan narrativo. Es una historia que tiene su ángulo de enfoque en Mrs. Hope, y aunque está narrada en tercera persona, es todo un triunfo de su punto de vista, pues nada de lo que se nos hace saber se escapa a su óptica pasional, unilateral y tal vez muy deformante. Este cuento jamesiano, que relata la supuesta rivalidad de dos escritores a través de la óptica de la viuda de uno de ellos (los personajes de James son a menudo intelectuales, como los de Borges), puede considerarse como un precedente de dos cuentos más de este último: «El duelo», basado en la rivalidad de dos pintoras, y "Guayaquil», donde los rivales son dos historiadores.

Ambigijedad y punto de vista son fundamentales también en Joseph Conrad, a quien Borges considera el mayor novelista inglés. Personajes como Lord Jim o Razumov (este último figura en Under Western Eyes) son ambiguos $y$, en el fondo, indescifrables. En el cuento «La otra muerte» Borges insinúa que, al menos literariamente, el hombre de quien no puede decirse con seguridad si es héroe o traidor, si es animoso o cobarde, ya que en momentos distintos se ha demostrado capaz de ambos contrarios, es más interesante que un hombre de una sola pieza como Martín Fierro. Borges hace explícita alusión a los personajes conradianos antes mencionados. En efecto, Pedro Damián, el personaje de «La otra muerte», está modelado sobre los héroes imperscrutables de Conrad, sobre su duplicidad, irreductible a una definición unívoca. En este mismo cuento la huella conradiana se percibe asimismo en la multiplicación de narradores y puntos de vista (que se contradicen hasta en el ámbito de un mismo narrador), lo cual puede recordar el caso-límite de Chance, novela a la que alude un par de veces el mismo Borges ${ }^{59}$.

En la literatura inglesa parece como si Borges buscara una medida distinta: una medida distinta de la latina, dominada en los últimos si-

58 Borges at Eighty, edic. ital. cit., pp. 102-103; Borges en diálogo, cit., pp. 71-72.

59 Richard Burgin, Conversations..., ed. ital. cit., pp. 54-55; Intervista BorgesArbasino, en L'approdo letterario, Roma, núms. 79-80 (1977), p. 284. 
glos por los modelos gálicos; una medida «germánica» que, cuando joven, fue a buscar vanamente en la literatura alemana moderna, que lo decepcionó por resultarle afectada por un romanticismo enfermizo ${ }^{60}$. Es por eso que, entre los poetas ingleses, ha valorado sobre todo a Robert Browning, que le parece el más alejado de la sensualidad verbal francesa. En su Introducción a la literatura inglesa, Borges destaca que Browning, a diferencia de Tennyson, trató de restablecer la aspereza sajona del verso ${ }^{61}$. $Y$ en la que es acaso la mayor novedad de sus composiciones poéticas, es decir, en los monólogos de sus personajes históricos e imaginarios, Browning fue como Dante, como Shakespeare, porque «se puso docenas de almas (algunas viles como la de Calibán y otras absurdas), y les versificó una serie de apasionadas alegaciones, justificándolas ante Dios» ${ }^{62}$. Pocos poetas profundizaron tanto como lo hizo él en estos soliloquios, por medio de los cuales cada alma reafirma su unicidad y trata de penetrar el enigma de su propio destino ${ }^{63}$. El modelo del soliloquio a la manera de Browning actúa en numerosos poemas de Borges, como «Poema conjetural», «El guardián de los libros», «Tamerlán», etc. En la composición titulada «Browning resuelve ser poeta», el autor hace pronunciar a Browning un monólogo al estilo de Browning. $\mathrm{Y}$ en el prólogo a «El otro, el mismo», se nos previene que en el «Poema conjetural» debe advertirse la influencia de los monólogos dramáticos de Robert Browning.

Las afinidades de Borges con el autor de Men and Women se manifiesta desde Inquisiciones (1925), donde se recoge un importante artículo titulado «Acerca de Unamuno, poeta» ${ }^{64}$. En él se establece un deslinde entre dos categorías opuestas de escritores, para cuya definición se recurre a vocablos hispánicos tradicionales como «culterano» y «conceptista». Están incluidos en el grupo de los culteranos Rimbaud, Swimburne, Herrera y Reissig; en el de los conceptistas, Hegel, Browning, Almafuerte, Unamuno. Los primeros son arduos (a veces oscuros) en un nivel meramente verbal; los segundos 10 son también, pues siguen «con más veracidad las corvaduras de un pensamiento complejo». Borges (huelga decirlo) se siente más solicitado por las contorsiones intelectuales de los segundos que por el llamativo rebuscamiento idiomático de los primeros.

${ }^{60}$ An Autobiographical Essay, ed. ital. cit., p. 147.

${ }^{61}$ Introducción a la literatura inglesa, cit., p. 841.

62 El tamaño de mi esperanza, cit., p. 32.

63 Ibidem, pp. 102 y 152.

64 Inquisiciones (Buenos Aires: Proa, 1925), pp. 100-108. 
Es posible que el mismo Unamuno, polémico contra los modernistas, casi todos francófilos, y declaradamente solidario con la poesía meditativa inglesa y, en particular, con Robert Browning, haya sugerido inicialmente tanto la distinción como los ejemplos que Borges propone. Hasta la admiración hacia aquellos versos que vibran de humanidad como un alma («los versos de veras», los define en $E l$ tamaño de mi esperanza -1926 - y nombra al Salmista, a Jorge Manrique, a Dante, a Browning, a Whitman, a José Hernández y al mismo Unamuno) ${ }^{65}$, parece ser, en el primer Borges, un rasgo que, si no procede directamente de la poética unamuniana, coincide por lo menos con ella. En otro pasaje del mismo libro opina que casi toda la lírica se alimenta de idola fori (embustes de la plaza) y que se salvan sólo algunos versos de Quevedo, Browning, Whitman y Unamuno ${ }^{66}$ : la restricción es deliberadamente exagerada para que el acercamiento de tales nombres adquiera mayor resalte.

No asombre a nadie la larga proyección de estas ideas (a pesar de reajustes y atenuaciones), si es que en el prólogo de un libro de poemas tardío, La cifra (1981), el poeta vuelve a juntar el nombre de Browning con los de Unamuno, Emerson y Robert Frost, es decir, con una serie de escritores que han practicado una poesía bastante similar a la suya, y que aquí denomina «intelectual», oponiéndola a la meramente verbal, que lo seduce menos y que de todos modos le estaría vedada por sus incapacidades. Por tanto, la ejemplaridad de Browning se ha mantenido inalterada durante muchos decenios en la opinión del escritor argentino, desde los ensayos juveniles hasta los versos de los últimos años, como demuestra, en estructura y contenido, el monólogo pronunciado por el «personaje» Góngora en el último libro de poemas, Los conjurados (1985).

En resumidas cuentas, no hay poeta inglés posterior a Coleridge que importe más que Browning en la teoría y en la práctica poética borgesiana. El representa, para nuestro escritor, una idea de la poesía que no sólo nos da el reverso del modelo francés, tan imitado por los poetas hispánicos, sino que se aparta también del mismo musicalísimo filón inglés que arranca de Tennyson y alcanza su apogeo en los prerrafaelistas y en Yeats. Aunque esta veta pueda a veces gustarle (no faltan referencias admirativas a la belleza de ciertas soluciones de Tennyson, Rossetti, Morris, Swimburne, Yeats), él tiende a rebajar lo que él llama lo meramente verbal, pues sus simpatías y afinidades (de algún modo, «calvinistas») lo empujan hacia lo ético (y lo heroico).

${ }^{65}$ El tamaño de mi esperanza, cit., p. 78.

66 Ibidem, p. 114. 
En efecto, Borges leyó, ya en sus años ginebrinos, un libro fundamental para su formación: el Sartor Resartus de Thomas Carlyle, y quedó tempranamente marcado por esa lectura, así como por otras obras del escritor escocés. Es verdad que el mito consciente de Carlyle no fue duradero en él. Su prosa ardiente y romántica fue el primer aspecto destinado a caer en la estimación de Borges, quien se acercaba progresivamente a un ideal clásico de escritura. Luego se dejó convencer, irreversiblemente, por Chesterton y Russell, que vieron en Carlyle al precursor $y$ hasta al inventor, junto con Fichte, del nazismo ${ }^{67}$. Sin embargo, a pesar del firme rechazo de la prosa volcánica y de la visión política de este escritor, algo carlyliano, quedó grabado para siempre en el fondo de él.

Por lo pronto, se adhiere a la opinión de Spencer según la cual Carlyle, aunque creyó abjurar de la fe presbiteriana de sus padres, no dejó nunca de ser un hombre profundamente ético, como demuestra su concepto del mundo, del hombre y de la conducta humana, heredado de un calvinismo rígido y pesimista ${ }^{68}$. De esta faceta de la personalidad de Carlyle, que, sin embargo, está ligada a su radical desconfianza en la democracia, Borges no llega a pronunciar condenación alguna, pues él mismo se define hombre esencialmente ético y más próximo al sentido de la ética personal y social propia de los países protestantes que al conciliante escepticismo moral de los países latinos. La figura intelectual de Carlyle, pues, con ser tan excesiva, estriba sobre una visión del universo y del proceder humano que de ningún modo es ajena a Borges.

Una sentencia de Carlyle, que manifiesta apreciar muchísimo, es que «toda obra humana es deleznable, pero la ejecución de esa obra es importante» ${ }^{69}$. En el prólogo a una edición argentina de De los héroes, Borges comenta ese dictamen, afirmando que «nadie ha sentido como Carlyle que este mundo es irreal (irreal como las pesadillas, y atroz). De esa fantasmagoría general rescata una sola cosa, el trabajo: no su resultado, entiéndase bien, que es mera vanidad, mera imagen, sino su ejecución ${ }^{70}$. De esta aclaración puede desprenderse que Borges aprecia (y comparte) la profunda eticidad de Carlyle, arraigada en una visión desconsolada pero sincera (y no trivialmente utilitarista) del mundo.

En el curso de este trabajo ya hemos tenido la oportunidad de señalar la coincidencia de Unamuno y Borges en el interés por Robert

${ }^{67}$ Otras inquisiciones, cit., pp. 180-182; Prólogos, cit., p. 35.

68 Prólogos, cit., pp. 33 y 35; El libro de arena, cit., p. 140.

69 María Esther Vázquez, op. cit., p. 61; Los conjurados (Madrid: Alianza, 1985), p. 13.

70 Prólogos, cit., p. 37. 
Browning. Aún más estrecha aparece tal convergencia respecto a Carlyle. Unamuno es tal vez el antecedente hispánico más importante y similar de este evidente influjo carlyliano sobre Borges. Es posible que el joven Borges haya sido influido, simultáneamente $o$ en tiempos distintos, por Carlyle y por el carlylismo unamuniano. Unamuno tradujo la Historia de la revolución francesa y amó la expresividad estilística de esa prosa, pero sobre todo compartió la angustia de Carlyle por el misterio del tiempo y de la eternidad, por la vida como sueño vano, por la sucesión enigmática de los acontecimientos históricos. E1 Don Quijote de Unamuno es, sin más, un héroe carlyliano, como bien vio Carlos Clavería ${ }^{71}$. El punto en que Unamuno y Borges más se aproximan al autor del Sartor resartus, es el pensamiento de que los hombres no son más que sueños o piezas o muñecos de un Dios desconocido, que actúa como una especie de titiritero, de Maese Pedro de la historia. El famoso verso de La tempestad shakespeariana, «we are such stuff as Dreams are made off», ha sido una cita favorita en el Sartor resartus, antes de llegar a serlo en las obras de Unamuno y de Borges.

Después de Carlyle, es la voz de Stevenson, cuyas consideraciones sobre ética, contenidas en sus Ethical Studies o esparcidas en su obra narrativa y poética, marcaron profundamente a Borges. Cuando en una entrevista se le rogó comentar ese versículo de «Fragmentos de un Evangelio apócrifo» en que se recomienda no juzgar al árbol por sus frutos ni al hombre por sus obras, ya que éstas pueden ser peores o mejores que él, nuestro escritor no vaciló en decir que era Stevenson la fuente de esa máxima ${ }^{72}$. Pensemos, por ejemplo, en el cuento «Markheim», cuando el asesino, defendiéndose frente a su doble, afirma que su vida no es más que una mascarada y una calumnia de sí mismo, y que los hombres son mejores que el disfraz que crece encima de ellos y los ahoga. La fuerte preocupación ética, que también en el caso de Stevenson, Borges atribuye a las raíces puritanas, es una de las causas del poder de atracción que el escritor escocés ejerce sobre él, y se conexiona con esa primacía ética de los pueblos protestantes sobre los católicos que no se cansa de subrayar.

Una profunda eticidad encuentra Borges en la obra de otros autores: especialmente de Conrad, de Kipling y de Shaw. Y junto con la ética, una dimensión épica o heroica que el gran público cree desaparecida de la

71 Carlos Clavería, Temas de Unamuno (Madrid: Gredos, 1953), pp. 9-58. Esencial para lo desarrollado en este párrafo, todo el largo análisis comparativo de Clavería sobre Unamuno y Carlyle.

72 Borges el memorioso, cit., p. 140. 
literatura contemporánea. Pero, según Borges, la narrativa de Conrad, la narrativa y la poesía de Kipling, la poesía de Chesterton ${ }^{73}$, han salvado lo épico en nuestro siglo antiépico. E, inopinadamente, el mismo George Bernard Shaw, considerado injustamente en la Argentina como un mero humorista, se ha revelado como uno de los pocos creadores de personajes heroicos de nuestro tiempo, personajes que, aunque privados de un nimbo romántico, suscitan nuestra admiración: Major Barbara, Lavinia, Keegan, Richard Dudgeon, Bluntschli, Caesar, Saint Joan ${ }^{74}$. La literatura inglesa conserva, por tanto, en una medida acaso mayor que las otras, ese espíritu épico, lejano descendiente de baladas y sagas anglosajonas y escandinavas, capaz de suscitar en Borges una verdadera conmoción (objetivo que los géneros patéticos siempre han ostentado ${ }^{75}$.

73 Borges admira la poesía de Kipling, tanto la neoépica de Harpe song of the dane women, Chant pagan, The Runes of Wayland's Sword, como la popular Barrack Room Ballads. El Hymn to Physical Pain del poeta inglés puede haber influido la actitud estoica del Poema de los dones o de Elogio de la sombra. En cuanto a Chesterton, alaba las baladas, White Horse y Lepanto, en las que pueden hallarse (afirma) metáforas de gran vigor imaginativo, dignas de la pluma de Víctor Hugo.

${ }^{74}$ Estos personajes se encuentran, en el orden antes citado, en las obras siguientes: Major Barbara; Androcles and the Lion; John Bull's Other Island; The devil's disciple; Arms and the Man; Caesar and Cleopatra; Saint Joan.

75 María Esther Vázquez, op. cit., p. 86. 